\title{
Remote memory for visuospatial information in patients with Huntington's disease
}

\author{
WILLIAM W. BEATTY \\ North Dakota State University, Fargo, North Dakota \\ and Neuropsychiatric Research Institute, Fargo, North Dakota
}

\begin{abstract}
Remote memory for visuospatial information was studied in patients with Huntington's disease (HD) using a recently developed test of geographical knowledge. When asked to locate places on a map of the region of the U.S. in which they were born and raised or on a map of California where they currently resided, the HD patients performed less accurately than controls, and the magnitude of their impairment was equally severe on both regional maps. The "flat" temporal gradient of the HD patients' retrograde amnesia for visuospatial information was similar in form to their performance in a previous study in which remote memory was measured using identification of famous faces and recall of public events. A second experiment demonstrated that visuomotor impairments could not account for the HD patients' deficits in geographical knowledge.
\end{abstract}

In previous studies of remote memory in brain-damaged patients, tests that require identification of famous persons or recall of public events have usually been employed. On such measures, patients with Huntington's disease (HD) consistently display a pattern of retrograde amnesia (RA) in which the loss of information is equally severe for all past decades (Albert, Butters, \& Brandt, 1981a, 1981b; Beatty, Salmon, Butters, Heindel, \& Granholm, 1988).

Remote memory for visuospatial information can be studied by asking subjects to locate places on maps. Using this approach, Beatty (1989) studied the development of geographical knowledge in groups of normal subjects ranging in age from their 20s to 70 and older. Accuracy in locating cities in the tristate region in which the subjects lived increased until the age of $\mathbf{3 0}$ and remained stable thereafter, whereas accuracy in locating U.S. cities outside of the home region matured more slowly, reaching asymptote at about age 50. In contrast, accuracy in locating gross features of U.S. geography (e.g., oceans) was near ceiling for all age groups. Both gender and education influenced overall performance, but changes in accuracy with age were similar for men and women and for groups varying in education. Other work with normal subjects suggests that once established, knowledge of the geography of a region in which one has resided is quite dur-

This research was supported by NIA Grant AG-05131 to the University of California, San Diego and by funds from the Medical Research Service of the Veterans Administration. The studies reported in this paper were conducted while the author was on sabbatical leave in the laboratory of Nelson Butters at UCSD. Dr. Butters's encouragement, support, and helpful comments on an earlier draft of the manuscript are gratefully acknowledged. Portions of these data were reported at the Annual Meeting of the International Neuropsychological Association, Denver, in February 1986. Address reprint requests to William W. Beatty, Department of Psychology, North Dakota State University, Fargo, ND 58105. able, persisting without apparent loss for at least 30 years after a person has moved away from an area of former residence (Beatty, 1985, 1988; Beatty \& Spangenberger, 1988).

In the first experiment reported here, RA for visuospatial information was examined by studying geographical knowledge of places of current or prior residence in a group of HD patients who were previously shown to exhibit a flat gradient of RA when asked to identify famous people or to recall past public events (Beatty, Salmon, et al., 1988). If the temporal pattern of RA for visuospatial information in HD is similar to that for other forms of knowledge, then HD patients should exhibit losses of geographical knowledge of regions of present and former residence that are equally severe in magnitude.

\section{EXPERIMENT 1}

\section{Method}

Subjects. Ten patients with HD ( 6 women, 4 men) were diagnosed by a board-certified neurologist on the basis of a positive family history and the presence of chorieform movements. They averaged 50.5 years of age (range: 29-70), 14.2 years of education (range: $10-18$ ), and 126.2 (range:104-143) on the Dementia Rating Scale (DRS; Mattis, 1976). Their full-scale IQs on the Wechsler Adult Intelligence Scale-Revised (Wechsler, 1981) averaged 86.5 (range: 73-99) and their MQs on the Wechsler Memory Scale (Wechsler, 1945) averaged 83.1 (range: 60-99). The HD patients had resided an average of 24.5 years in the region in which they were born and raised (range: 9-56), 13.7 years in California (range: 2-29), and 12.1 years in San Diego County (range: 2-29).

Normal controls (14 wornen, 12 men) were recruited through newspaper advertisements and were paid for their participation. Respondents with a history of alcoholism, drug abuse, learning disability, or neurologic or major psychiatric illness were excluded. Control subjects averaged 48.9 years of age (range: $24-75$ ), 14.6 years of education (range: 12-20), 27.6 years of residence in the region in which they were bom and raised (range: 7-68), 13.2 years of residence in California (range: $1-53$ ), and 10.2 years of residence in San Diego County (range: 1-53). There were no signifi- 
cant differences between the patients and the controls on any of the demographic variables (all $F \mathrm{~s}<1$ ). All subjects provided written informed consent after a thorough explanation of the procedures.

Materials and Procedures. All subjects completed the appropriate sections of the standard version of the Fargo Map Test (FMT-S; Beatty, 1988). These sections included residential history, the U.S. map, the California-Nevada (CA-NV) map, and the map of the region in which the subject was born and raised (hereafter designated Region 1). In addition, the subjects located 12 geographical features on an outline map of San Diego County, CA, which was developed for this study. On each map test, the subjects attempted to locate 12-14 features on outline maps by pointing to the features' locations or writing an appropriate code number at the spot on the map where they believed the feature was located. Since earlier studies (Beatty \& Tröster, 1987; Tröster, Beatty, Staton, \& Rorabaugh, 1989) have demonstrated high interrater reliabilities $(r \mathrm{~s}>.85$ ), only a single rater scored the map tests in the present study.

\section{Results and Discussion}

Performance by the HD patients and their matched controls is summarized in Table 1 . A 2 (groups) $\times 2$ (regions) analysis of variance (ANOVA) revealed a significant main effect of groups $[F(1,34)=6.73, p<.05]$, but neither the main effect of regions nor the groups $\times$ regions interaction approached significance $(F \mathrm{~s}<1)$. Additional analyses showed that the HD patients were significantly less accurate than the controls in locating places on maps of Region $1[F(1,34)=5.30, p<.05]$, Region 2 [i.e., CA-NV, $F(1,34)=6.46, p<.05]$, and San Diego County $[F(1,34)=5.85, p<.05]$. Within-group comparisons confirmed the impression that for both the HD patients and the controls, levels of accuracy on maps of Region 1, where they had formerly lived, and on the map of CA-NV, where they currently lived, were similar $(F \mathrm{~s}<1)$. This occurred despite the fact that the subjects had not resided in Region 1 for more than 15 years $(M$ $=19.1$ years for HD patients vs. 17.3 years for controls). In contrast, the HD patients were not significantly impaired in locating features on the U.S. map test $(F=1.67$, n.s.).

In agreement with earlier findings (Beatty, 1985, 1988; Beatty \& Spangenberger, 1988), the normal controls exhibited similar levels of accuracy in locating places on maps of regions of previous and current residence. This finding is consistent with the view that geographical knowledge of the sort measured by the FMT-S is a persistent form of visuospatial memory.

The HD patients also demonstrated equivalent knowledge of Regions 1 and 2, but their overall level of

Table 1

Percentage of Correct Responses on Measures of Geographical Knowledge in Experiment 1

\begin{tabular}{lrrrrr} 
& \multicolumn{2}{c}{ HD Patients } & & \multicolumn{2}{c}{ Controls } \\
\cline { 6 - 6 } \cline { 5 - 6 } Map Test & $M$ & \multicolumn{1}{c}{$S D$} & & $M$ & \multicolumn{1}{c}{$S D$} \\
\hline U.S. Map & 89.3 & 9.6 & & 93.7 & 7.9 \\
Region 1 Map & 56.8 & 26.2 & 73.2 & 16.3 \\
Region 2 Map (CA-NV) & 51.4 & 15.0 & 69.3 & 20.1 \\
San Diego County Map & 49.3 & 20.5 & & 72.8 & 27.9 \\
\hline
\end{tabular}

Note-HD = Huntington's disease accuracy in locating places on both regional maps (as well as on the San Diego County map) was inferior to that of the controls. As a result, the HD patients exhibited a flat temporal gradient of RA for visuospatial information that is quite similar in form to the pattern of RA previously reported for the same patients on a test measuring knowledge of famous persons and current events (Beatty, Salmon, et al., 1988). The most obvious interpretation of the present findings is that, in HD, the temporal gradient of RA is similar for different kinds of premorbidly acquired information.

There is, however, an alternative interpretation of these results. Accurate performance on the FMT-S demands that the subject be able to write or point to the spot on the outline map where he or she believes the target feature is located. Thus, problems in eye-hand coordination, which can accompany the chorieform movements associated with HD, could produce deficits in performance that are unrelated to the loss of memory for visuospatial information. Ten of the 14 targets on the U.S. maps are gross features of U.S. geography (e.g., oceans), whereas the majority of items on the regional and San Diego County maps are specific "points" (e.g., cities), which require more precise localization. Thus, the present findings that HD patients were impaired on regional maps but performed normally on the U.S. map could be attributed to the differential impact of impaired visuomotor function on the various tests of geographical knowledge that constitute the FMT-S. In the second experiment, this visuomotor control hypothesis was evaluated by employing a test of geographical knowledge designed to minimize the potential influence of disturbances in the execution of skilled hand movements.

\section{EXPERIMENT 2}

\section{Method}

Subjects. Seven HD patients ( 3 women, 4 men) were selected using the same criteria as in Experiment 1 . They averaged 56.7 years of age (range: 44-70), 14.9 years of education (range: 10-18), and 125.4 (range: 104-142) on the DRS. The normal controls (6 women, 9 men) were screened as described in Experiment 1; they averaged 57.2 years of age (range: $32-75$ ) and 14.7 years of education (range: 11-18). Five of the HD patients and 7 of the controls had also served in the first experiment; the two testing sessions were separated by at least 2 months and no feedback was given regarding the subjects' performance on the initial series of tests. Within both patient and control groups, the average performance of the subjects who had been tested earlier in Experiment 1 was almost identical to that of the subjects who had not received those tests. Hence, it is unlikely that practice effects contaminated the results.

Materials and Procedures. All subjects received the revised version of the FMT (FMT-R; Beatty, 1988). This test requires locating 30 U.S. cities and 10 gross features (e.g., Canada, Florida) of U.S. geography on an outline map of the 48 contiguous U.S. states. There were no state boundaries on the map. Arranged on the map were 46 numbered dots. Thirty of the dots corresponded to the actual locations of target cities. The remaining 16 dots were distractors. The subjects responded by writing (or saying) the number that corresponded to the presumed location of the target city. Then they indicated the location of the 10 gross features (again by 
Table 2

Percentage of Correct Responses on Measures of Geographical Knowledge in Experiment 2

\begin{tabular}{lllll}
\hline & \multicolumn{2}{c}{ HD Patients } & & \multicolumn{2}{c}{ Controls } \\
\cline { 2 - 3 } \cline { 5 - 5 } Feature Tested & $M$ & $S D$ & $M$ & $S D$ \\
\hline Gross Features of & & & & \\
U.S. Geography & 94.0 & 7.3 & 97.0 & 6.1 \\
U.S. Cities & & & & \\
$\quad$ Overall & 53.3 & 19.0 & 80.0 & 13.6 \\
Far West & 72.0 & 21.2 & 90.0 & 12.4 \\
South West & 52.0 & 21.2 & 76.0 & 19.1 \\
North Central & 38.0 & 17.9 & 74.0 & 23.3 \\
Mid West & 40.0 & 19.3 & 76.0 & 20.2 \\
East & 64.0 & 31.2 & 84.0 & 20.2 \\
South East & 58.0 & 30.7 & 80.0 & 15.5 \\
\hline
\end{tabular}

Note-HD $=$ Huntington's disease.

writing an appropriate code letter or pointing to the presumed location).

\section{Results and Discussion}

As shown in Table 2, the HD patients accurately located fewer U.S. cities than did the controls $[F(1,20)=$ $14.26, p<.005$ ], but they were not significantly impaired in locating gross features of U.S. geography $(F<1)$. To determine whether or not the patients' difficulty in locating cities was restricted to a particular section of the country, the 30 U.S. cities were grouped into six geographical regions of five cities each. A groups $X$ regions ANOVA revealed significant main effects of groups $[F(1,20)=14.26, p<.005]$ and regions $[F(5,600)=3.58, p<.01]$, but the groups $\times$ regions interaction was not significant $(F<1)$. Both the HD patients and the controls were more accurate in locating cities near the east and west coasts than those located in the middle regions of the country, but the magnitude of the difference between the HD patients and the controls was similar for all regions of the country.

The present findings demonstrate that impairments in visuomotor functioning cannot account for the $\mathrm{HD}$ patients' poor performance on tests of geographical knowledge.

\section{GENERAL DISCUSSION}

The results of Experiment 1 demonstrated that HD patients exhibit deficits in remote memory for visuospatial information, and that the severity of their impairments was not related to the temporal period when the information was acquired. Thus, the flat temporal gradient of RA, previously demonstrated when HD patients are required to recall premorbidly acquired knowledge about faces and events (Albert et al., 1981a, 1981b; Beatty, Salmon, et al., 1988) appears to apply to information about the location of places as well. These findings encourage the view that the remote-memory impairments of HD patients arise from derangement of a common mechanism or mechanisms essential for the recall of established knowledge from a variety of different domains. This con- clusion should be regarded as tentative, since geographical knowledge was measured at two points in time that spanned relatively lengthy periods.

Although the HD patients performed poorly on the regional maps and the map of San Diego County, they located gross features of U.S. geography as accurately as did the controls. Since normal subjects reach asymptotic performance on tests requiring localization of gross features during their $20 \mathrm{~s}$, at an age when knowledge of more precise features of geography (i.e., regional and U.S. cities) is still increasing (Beatty, 1989), it could be argued that HD patients do, in fact, exhibit relative preservation of their oldest visuospatial memories. Although this explanation is logically plausible, the counterargumentnamely, that $\mathrm{HD}$ patients exhibit normal recall of the gross features of U.S. geography because of ceiling effects-is equally reasonable.

The results of Experiment 2 indicated that deficits in visuomotor coordination could not explain the $\mathrm{HD}$ patients' impairments in geographical memory, but this experiment did not address the possibility that defective visuospatial perception might account for the patients' poor performance on the map tests. Although this explanation cannot be firmly rejected, considerable evidence indicates that HD patients exhibit deficits on tasks that demand accurate egocentric spatial orientation, but perform almost normally on tests that measure allocentric spatial orientation (Brouwers, Cox, Martin, Chase, \& Fedio, 1984; Fedio, Cox, Neophytides, Canal-Frederick, \& Chase, 1979; Potegal, 1971). Accurate performance on tests of geographical knowledge appears to tap allocentric orientation more than egocentric orientation, and this impression is supported by the absence of a significant relationship between geographical knowledge and performance on a pathfinding test (a measure of egocentric orientation) among undergraduate students (Beatty \& Tröster, 1987).

On the basis of the similarity of the patterns of patient performance on neuropsychological tests, HD, Parkinson's disease (PD), and multiple sclerosis (MS) have been considered to be forms of "subcortical dementia" (Cummings \& Benson, 1984; Rao, 1986). The deficits in remote memory for visuospatial information exhibited by HD patients tested in the present study are also evident in patients with PD or chronic progressive MS (Beatty, Goodkin, Monson, Beatty, \& Hertsgaard, 1988; Beatty \& Monson, 1989). Together, these findings suggest that loss of geographical knowledge may be a general consequence of subcortical dementia, whatever its specific etiology. Because the studies of geographical knowledge in the PD and MS patients were conducted in North Dakota, a sparsely populated state with negligible inward migration, it was not practical to determine the temporal patterns of RA for visuospatial information for the MS and PD patients. A flat temporal gradient would be predicted, since this pattern has been observed when MS or PD patients were asked to identify famous people or to recall public events (Beatty, Goodkin, et al., 1988; Freedman, 
Rivoira, Butters, Sax, \& Feldman, 1984; Huber, Shuttleworth, \& Paulson, 1986; but see Sagar, Cohen, Sullivan, Corkin, \& Growdon, 1988).

\section{REFERENCES}

Albert, M. S., Butters, N., \& Brandt, J. (1981a). Development of remote memory loss in patients with Huntington's disease. Journal of Clinical Neuropsychology, 3, 1-12.

Albert, M. S., Butters, N., \& Brandt, J. (1981b). Pattems of remote memory in amnesic and demented patients. Archives of Neurology, 38, 495-500.

BeAtTY, W. W. (1985). Assessing remote memory for space: The Fargo map test. Journal of Clinical \& Experimental Neuropsychology, 7(Abstract No. 168), 640.

Beatty, W. W. (1988). The Fargo map test: A standardized method for assessing remote memory for visuospatial information. Journal of Clinical Psychology, 44, 61-67.

BeAtTY, W. W. (1989). Geographical knowledge throughout the lifespan. Bulletin of the Psychonomic Society, 27, 379-381.

Beatty, W. W., Goodkin, D. E., Monson, N., Beatty, P. A., \& HERTSGAARD, D. (1988). Anterograde and retrograde amnesia in patients with chronic progressive multiple sclerosis. Archives of $\mathrm{Neu}$ rology, 45, 611-619.

Beatty, W. W., Monson, N. (1989). Geographical knowledge in patients with Parkinson's disease. Bulletin of the Psychonomic Society, 27, 473-475.

Beatty, W. W., Salmon, D. P., Butters, N., Heindel, W. C., \& GranHoLm, E. L. (1988). Retrograde amnesia in patients with Alzheimer's disease or Huntington's disease. Neurobiology of Aging, 9, 181-186.

Beatty, W. W., \& Spangenderger, M. (1988). Persistence of geographical memories in adults. Bulletin of the Psychonomic Society, 26, 104-105.

Beatty, W. W., \& Tröster, A. I. (1987). Gender differences in geographical knowledge. Sex Roles, 16, 565-590.
Brouwers, P., Cox, C., Martin, A., Chase, T., Fedio, P. (1984). Differential perceptual-spatial impairment in Huntington's and Alzheimer's dementias. Archives of Neurology, 41, 1073-1076.

Cummings, J. L., \& Benson, D. F. (1984). Subcortical dementia: Review of an emerging concept. Archives of Neurology, 41, 874-879.

Fedio, P., Cox, C. S., Neophytides, A., Canal-Frederick, G., Chase, T. N. (1979). Neuropsychological profile of Huntington's disease: Patients and those at risk. In T. N. Chase, N. S. Wexler, \& A. Barbeau (Eds.), Advances in neurology: Vol. 23. Huntington's disease (pp. 239-255). New York: Raven.

Freedman, M., Rivoira, P., Butters, N., Sax, D. S., Feldman, R. S. (1984). Retrograde amnesia in Parkinson's disease. Canadian Joumal of Neurological Sciences, 11, 297-301.

Huber, S. J., Shuttleworth, E. C., \& Paulson, G. W. (1986). Dementia in Parkinson's disease. Archives of Neurology, 43, 987-990.

MAtTIS, S. (1976). Mental status examination for organic mental syndrome in the elderly patient. In L. Bellack \& T. B. Karasu (Eds.), Geriatric psychiatry (pp. 77-121). New York: Grune \& Stratton.

Potegal, M. (1971). A note on the spatial-motor deficits in patients with Huntington's disease: A test of a hypothesis. Neuropsychologia, 9, 233-235.

RAo, S. M. (1986). Neuropsychology of multiple sclerosis: A critical review. Journal of Clinical \& Experimental Neuropsychology, 8 , 503-542.

Sagar, H. J., Cohen, N. J., Sullivan, E. V., Corkin, S., \& GrowDON, J. H. (1988). Remote memory function in Alzheimer's disease and Parkinson's disease. Brain, 111, 185-206.

Tröster, A. I., Beatty, W. W., Staton, R. D., \& Rorabaugh, A. G. (1989). Effects of scopolamine on anterograde and remote memory in humans. Psychobiology, 17, 12-18.

WECHSLER, D. (1945). A standardized memory scale for clinical use. Journal of Psychology, 19, 87-95.

WECHSLER, D. (1981). The Wechsler adult intelligence scale revised. New York: The Psychological Corporation.

(Manuscript received March 21, 1989; revision accepted for publication July 19, 1989.) 